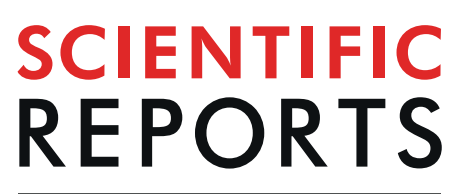

natureresearch

\title{
Nano-indentation reveals a potential role for gradients of cell wall stiffness in directional movement of the resurrection plant Selaginella lepidophylla
}

\author{
Meisam Asgari $\mathbb{C}^{1,2,4}$, Véronique Brulé ${ }^{3,4}$, Tamara L. Western ${ }^{3}$ \& Damiano Pasini ${ }^{1 *}$
}

As a physical response to water loss during drought, inner Selaginella lepidophylla stems curl into a spiral shape to prevent photoirradiation damage to their photosynthetic surfaces. Curling is reversible and involves hierarchical deformation, making S. lepidophylla an attractive model with which to study water-responsive actuation. Investigation at the organ and tissue level has led to the understanding that the direction and extent of stem curling can be partially attributed to stiffness gradients between adaxial and abaxial stem sides at the nanoscale. Here, we examine cell wall elasticity to understand how it contributes to the overall stem curling. We compare the measured elastic moduli along the stem length and between adaxial and abaxial stem sides using atomic force microscopy nano-indentation testing. We show that changes in cortex secondary cell wall development lead to cell wall stiffness gradients from stem tip to base, and also between adaxial and abaxial stem sides. Changes in cortical cell wall morphology and secondary cell wall composition are suggested to contribute to the observed stiffness gradients.

Nature is a perpetual source of inspiration for biomimetic and actuating devices ${ }^{1}$. Current biomimetic research involves a multi-scale approach to investigate how structural and mechanical properties at various length-scales determine organism function ${ }^{2}$. As more hierarchical models are studied, and their micro- and nanoscale properties better understood, more complex biomimetic and actuating devices can be designed ${ }^{2,3}$. Of the many organisms studied, plants are particularly interesting because of the wide range of functions and structures produced from a limited set of constituent materials, i.e. cell wall components ${ }^{4,5}$. Juxtapositions of different tissues and/or cell wall structures and compositions can drive organ movements in response to water or humidity. These include both rapid, 'active' actuation in response to changes in cellular turgor pressure in living tissues, or slower, 'passive', hygroscopic movements resulting from the shrinking and swelling of the cell walls themselves in living or dead organs $^{6-8}$.

Selaginella lepidophylla, a desiccation tolerant spikemoss, is a promising hierarchical model to study hygroscopic actuation ${ }^{9-11}$. S. lepidophylla plants consist of hundreds of stems developing in a spiral phyllotaxy that curl upon themselves when dehydrated (Fig. 1A,C). Curling is a physical mechanism to prevent thermal and photoirradiation damage to photosynthetic surfaces during prolonged periods of drought ${ }^{12,13}$. During desiccation, the stem tip curls toward the upper (adaxial) side, and away from the under (abaxial) side (Fig. 1B,C). Stem curling/uncurling is driven by differential swelling and shrinking of adaxial and abaxial stem sides in response to water gain or loss ${ }^{10,11}$. The main tissue involved in this process is the cortex, which comprises the bulk of the S. lepidophylla stem (Fig. 1B $)^{11}$. A thin epidermal layer and an amphicribral vascular bundle are also present; however, these tissues do not significantly contribute to the differential swelling and shrinking that drives stem curling/uncurling.

${ }^{1}$ Department of Mechanical Engineering, McGill University, 817 Sherbrooke Street West, Montréal, OC, H3A 0C3, Canada. ${ }^{2}$ Theoretical and Applied Mechanics Program, School of Engineering and Applied Science, Northwestern University, 2145 Sheridan Rd., Evanston, IL, 60208-3109, USA. ${ }^{3}$ Department of Biology, McGill University, 1205 Avenue Docteur Penfield, Montréal, OC, H3A 1B1, Canada. ${ }^{4}$ These authors contributed equally: Meisam Asgari and Véronique Brulé. *email: damiano.pasini@mcgill.ca 


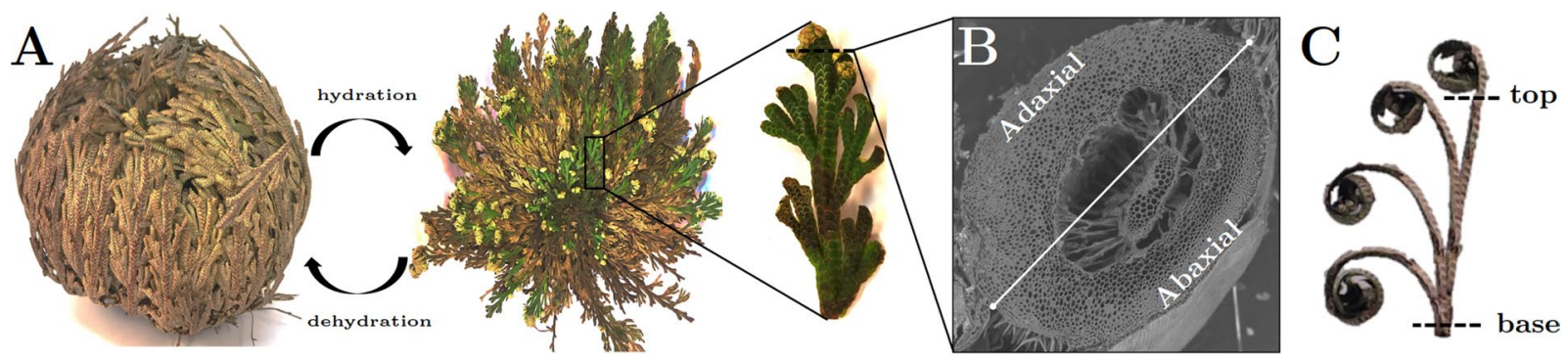

Figure 1. Water-Responsive Deformation in S. lepidophylla. (A) Mature S. lepidophylla plant showing dehydrated and hydrated conformations, as well as an isolated inner stem (inset). When dehydrated, S. lepidophylla appears as a ball of outer stems curled over its inner stems. When hydrated, stems are uncurled and lie flat in a spiral rosette; (B) Transverse section from the apical region of an inner stem imaged with scanning electron microscopy. Adaxial (upper) and abaxial (lower) stem sides are indicated, with a white line bisecting the transition area. (C) Time-lapse images showing the pattern of reversible inner stem curling. As stems dry, the tip curls on itself toward the stem base to form a spiral conformation. Upon rehydration with water, this process is reversed.

Stiffness, defined as the ability of a material to resist deformation in response to an applied stress, determines the direction and extent of conformational changes undertaken by a material and hence is a critical mechanical property governing actuation response. The stiffer a material is, the less it deforms under a mechanical load. By layering or otherwise locally joining materials with dissimilar stiffness in a composite material, it is possible to control the global deformation in a specific direction ${ }^{14,15}$. Stiffness profiles leading to deformation in S. lepidophylla have been studied at the organ and tissue level ${ }^{10,11}$. Here, we present a complementary nanoscale investigation that sheds light on previously unexplored factors controlling the stiffness of S. lepidophylla in static and time-varying loads. The specific focus is on the elastic moduli of cortical cell walls, and the aim is to understand their contribution to the observed direction and degree of curling of inner stems. We take advantage of atomic force microscopy (AFM), a technique frequently used to study plant cell wall mechanics ${ }^{16-18}$. In particular, we use AFM indentation to locally measure the nanoscale elastic properties of cell walls, as well as to assess the level of inhomogeneity and stiffness gradients of the tissue across representative transverse sections of the plant, both longitudinally (stem tip to base) and between adaxial and abaxial stem sides. We also preliminarily investigate the viscoelastic behaviour at given loading rates.

\section{Materials and Methods}

Plant materials. Mature S. lepidophylla plants were purchased from Canadian Air Plants (New Brunswick, Canada), and maintained in a desiccated state at $25^{\circ} \mathrm{C}$ and $\sim 30-50 \%$ relative humidity until use. Prior to experimentation, S. lepidophylla plants were placed in a plate of water and allowed to rehydrate for three consecutive days to achieve $100 \%$ relative water content.

Time-lapse video capture. Video capture was adapted from the protocol in Rafsanjani et al. ${ }^{10}$. Time-lapse videos were captured using a Logitech C920 HD Pro Webcam (1080p, Carl Zeiss optics) and Video Velocity Time-Lapse Studio software (Candylabs). S. lepidophylla plants were allowed to rehydrate for 24 hours. Individual inner stems were cut from the plant at the root-stem interface and secured in a metal clamp, which was affixed to the base of a square Petri dish. Stems were then allowed to air-dry for approximately 6 hours, during which time changes in their curvature were captured via time-lapse filming at frame rate of $1 \mathrm{~min} 21 \mathrm{~s}$. Stems were taken from four different S. lepidophylla plants. In total, four inner stems were tested and displayed similar curling/uncurling patterns.

Histochemical and immunological analysis of cell wall composition. A total of ten inner stems from five individual plants were isolated and cut into five regions (top, top-middle, middle, middle-base, and base). For lignin detection and cell wall counter-staining, samples were fixed with FAA (formaldehyde:acetic acid:alcohol) solution for one week, dehydrated through an ethanol series, and embedded in paraffin. Following paraffin removal, thick sections $(1 \mu \mathrm{m})$ were stained with safranin $\mathrm{O}$ and alcian blue as outlined in Ruzin ${ }^{19}$.

A second set of ten inner stems from five individual plants were isolated and cut into five regions for immunohistochemical investigation. For pectin and hemicellulose detection, samples were fixed and embedded in London Resin White following the method outlined in Young et al. ${ }^{20}$. Samples were incubated at room temperature in a blocking solution [ $5 \%(\mathrm{w} / \mathrm{v})$ normal goat serum (NGS) in $1 \times$ Tris-buffered saline/0.2\% Tween (v/v) (TBST)] in a homemade humidity box for 40 minutes. Blocking solution was washed off using $1 \times$ TBST. Slides were then incubated with primary antibodies at $1: 10$ dilution $(\mathrm{v} / \mathrm{v})$ in $1 \%(\mathrm{w} / \mathrm{v})$ NGS blocking solution in the humidity box for 1 hour (antibodies are described below). Slides were washed $2 \times 20$ minutes in $1 \times$ TBST. Secondary antibodies were diluted at 1:100 (v/v) in 1\% (w/v) NGS blocking solution in the dark for 45 minutes. Slides were washed $2 \times 20$ minutes in the dark and mounted in $90 \%(\mathrm{v} / \mathrm{v})$ glycerol. Control slides were used to test the specificity of the secondary antibodies and also to test for autofluorescence. Blocked slides that were not incubated with primary or secondary antibodies were imaged, as well as slides blocked and incubated with only secondary antibody. LM10 (Rat IgG2c) and LM11 (Rat IgM) antibodies were obtained from Plant Probes, $\mathrm{UK}^{21}$. 
LM10 binds to unsubstituted or low-substituted xylan backbone chains, while LM11 is able to additionally bind to wheat arabinoxylan. JIM7 (Rat IgA) and JIM13 (Rat IgM) were obtained from the Complex Carbohydrate Research Centre ${ }^{22,23}$. JIM7 binds to partially methyl-esterified homogalacturonan and JIM13 binds to arabinogalactan and arabinogalactan protein. Alexa-fluor 488 secondary antibody was obtained from Invitrogen (goat anti-Rat IgG $(\mathrm{H}+\mathrm{L})$ polyclonal, CAT\# A-11006).

For cellulose detection, a total of five, fully hydrated S. lepidophylla stems were isolated from three different plants and embedded in polyethylene glycol (PEG) using the protocol from Gierlinger et al. ${ }^{24}$. Embedded samples were sectioned ( $10 \mu \mathrm{m}$ thickness) using a Leica RM2245 semi-automated rotary microtome. Solidified PEG was then removed using washes of $\mathrm{ddH}_{2} \mathrm{O}$. Samples were then prepared following the method outlined in Ruzin ${ }^{19}$ for calcofluor white staining.

All samples were imaged using a Leica DM6000B epifluorescence microscope (Leica Microsystems, Wetzlar Germany) and QImaging Retiga CCD camera with Openlab imaging software (QImaging, British Columbia Canada).

Scanning electron microscopy. Fresh, hand-cut sections $(\sim 1 \mathrm{~mm}$ thick $)$ from the apical stem region were mounted on SEM stubs and allowed to air-dry (at a relative humidity $\sim 30 \%$ ) for 24 hours prior to imaging. Dry sections were imaged using a Hitachi TM3030Plus SEM in backscatter electron mode.

Atomic force microscopy. A JPK Atomic Force Microscope (JPK Nano-wizard@3 Bio Science, Berlin, Germany) was used for imaging and force spectroscopy. S. lepidophylla stem samples (three stems, each from separate plants, with five regions per stem, and three replicate sections per region) were cut transversally using a sharp blade in a wet state. Sections ( $1 \mathrm{~mm}$ in thickness) were air-dried to ambient humidity ( $\sim 30 \%$ relative humidity $[\mathrm{RH}]$ ) and placed on double-sided clear tape on a microscope slide. Cortical stem tissue in adaxial and abaxial regions was located to perform force measurements. All the measurements were performed on tissue in $\sim 30 \% \mathrm{RH}$. Using the QI imaging mode of the JPK AFM, a number of force maps were created within the area of $30 \mu \mathrm{m} \times 30 \mu \mathrm{m}$ on each sample. Reduced scan areas were then selected to obtain the structural details of the cell walls in which $128 \times 128$ indentation points were tested in areas of $1-10 \mu \mathrm{m}^{2}$. The force maps averaged $3 \mu \mathrm{m}^{2}$ in size. For consistency we prescribed the indentation parameters (e.g. window size, number of points, indentation depth) within the cortical tissue area across stem sections and between adaxial and abaxial sides.

Three types of AFM probes were used for contact mode imaging: (1) Non-conductive silicon nitride cantilevers with integrated conical tips of radius $20 \mathrm{~nm}$ (MLCT Micro-cantilever, Bruker, Mannheim, Germany) [a spring constant of $0.06 \mathrm{~N} / \mathrm{m}$ and a resonance frequency of $22 \mathrm{kHz}$; (2) Biotool high resolution qp-BioAC/ Quartz cantilevers with a $2 \mathrm{~nm}$ defined conical tip (Nanotools USA LLC, Henderson, NV) [a $60 \mu \mathrm{m}$ length, a spring constant of $0.1 \mathrm{~N} / \mathrm{m}$ and a nominal resonance frequency of $50 \mathrm{kHz}$ ]; and (3) Super-sharp standard Force Modulation Mode Reflex Coating (FMR) cantilevers with diamond-like carbon nano-tip of radius 2-3 nm (Nanotools USA LLC, Henderson, NV) [a spring constant of $2.8 \mathrm{~N} / \mathrm{m}$, a nominal resonance frequency of $75 \mathrm{kHz}$ in air]. Non-Contact High Resonance (NCHR) cantilevers (Nanotools USA LLC, Henderson, NV) with a nominal spring constant of $40 \mathrm{~N} / \mathrm{m}$ and integrated spherical tip of radius $100 \mathrm{~nm}( \pm 10 \%)$ were applied for indentation measurements. The indentation frequency was $1-500 \mathrm{~Hz}$. The AFM measurements were performed in an ambient environment of $20-25^{\circ} \mathrm{C}$ and $\sim 30 \% \mathrm{RH}$. Prior to each indentation test, the deflection sensitivity of the AFM cantilever was calibrated by engaging the cantilever on the surface of a clean microscope slide ${ }^{25}$. The spring constant of the cantilever was then determined from the power spectral density of the thermal noise fluctuations in air by fitting the first free resonance peak of the AFM cantilever to that of a simple harmonic oscillator using the JPK software ${ }^{26}$.

Indentations were repeated at given locations to ensure that no permanent deformation occurred at the surface of the sample. Force maps containing $128 \times 128$ indentation points were created on each indentation area. The elastic modulus $E$ of a sample was obtained from the retracting force-indentation depth curve through Hertzian contact mechanics, where $E=3 F\left(1-\nu^{2}\right) / 4 \sqrt{R \delta^{3}}$ is the relation between the elastic modulus $E$ and the applied indenting load $F$ with $\nu$ being the Poisson's ratio of the sample, $R$ the radius of the AFM probe, and $\delta$ the indentation depth ${ }^{27}$. A number of assumptions were considered. The deformation of the sample relative to its thickness and also relative to the radius of the probe was assumed very small ${ }^{28}$. Any strain below the elastic limit was also assumed infinitesimal, a condition satisfied with the use of an indentation depth below $50 \mathrm{~nm}$ that rules out the influence of the glass substrate as well as any nonlinear and inelastic behaviour of the tissue at higher strains ${ }^{29,30}$. The Poisson's ratio $\nu$ was selected to be 0.5 . Data analysis was performed with the JPK data processing software. Statistical significance was determined by a paired Student's t-test, when applicable. Differences were considered significant at $\mathrm{p}<0.05$.

\section{Results and Discussion}

Cell wall appearance differs between adaxial and abaxial stem sides. Dried, transverse sections from a set of regions along the length of inner S. lepidophylla stems were scanned with AFM to generate topographical images of the adaxial and abaxial cortical cell walls (Fig. 2A,B; Supplementary Fig. 1). Overall, cortex cells appear round to oval in geometry, with no obvious change in cell shape between adaxial and abaxial stem sides or between tip and basal stem segments. Differences arise when comparing cell wall layering between adaxial and abaxial cortical cells. Abaxial cell walls show very distinct secondary cell wall layers, while those in the adaxial region appear relatively smooth. This pattern is observable in sections along the length of the stem and is also visible in cortical cell walls imaged with transmission electron microscopy (Supplementary Fig. 2). Typical dicot and gymnosperm secondary cell walls contain three layers (S1-S3, with S2 being the thickest layer) ${ }^{31-33}$. In some monocots, such as bamboo species, more layers are visible. Bamboo fibers can have up to six to eight distinct cell wall layers ${ }^{33-36}$. Qualitatively, S. lepidophylla cortical cells walls, especially those on the abaxial stem side, 

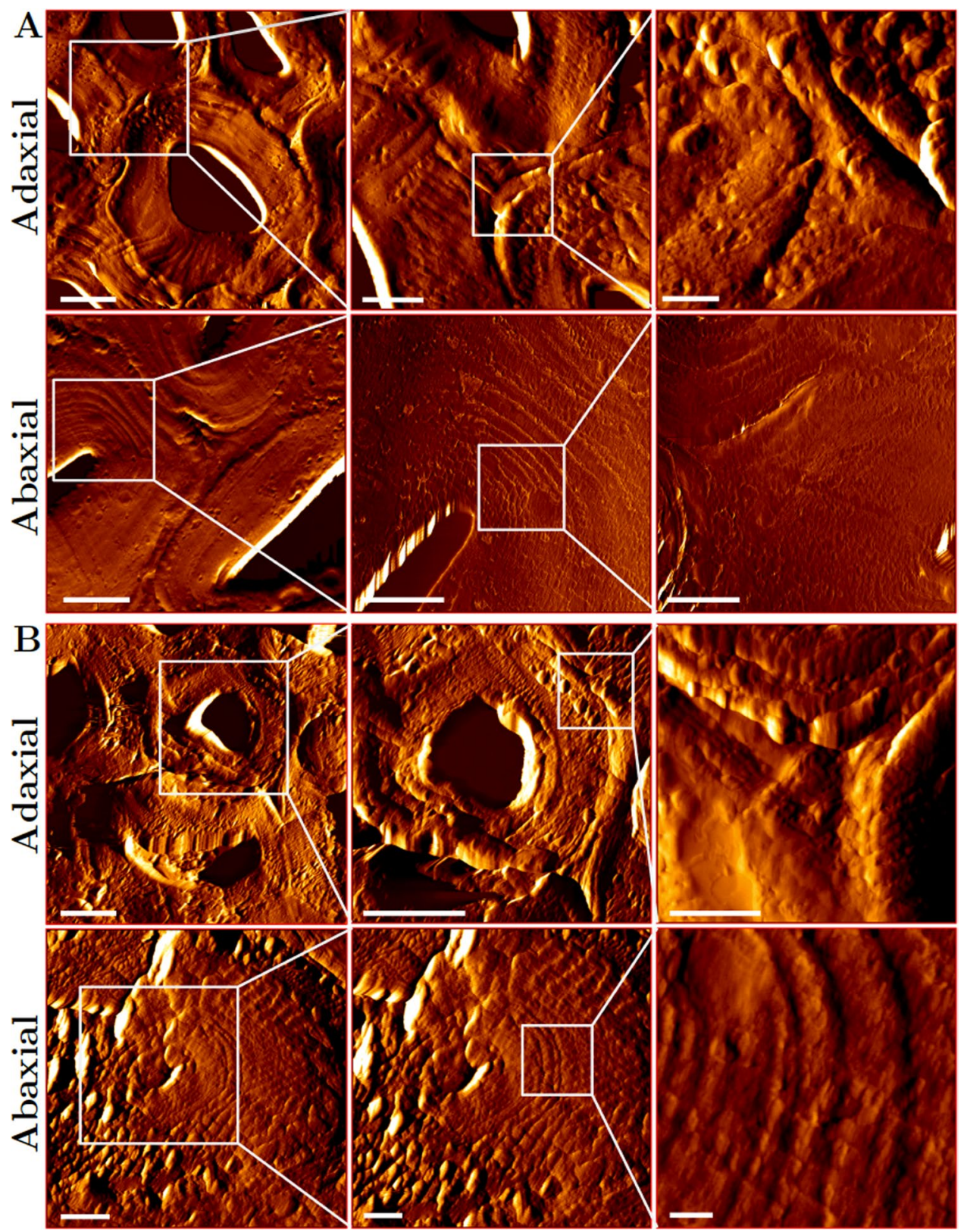

Figure 2. Cell Wall Layering in S. lepidophylla Cortex. AFM topological scans of apical (A) and basal (B) regions showing adaxial and abaxial cell shape and cell wall layering. Abaxial cell walls in both apical and basal stem regions show more prominent layering than in adaxial cell walls. Scale bars from left to right represent $5 \mu \mathrm{m}, 2 \mu \mathrm{m}$, and $500 \mathrm{~nm}$.

appear to have more than three SCW layers, and therefore resemble bamboo with respect to cell wall layer morphology. Compared to adjacent cell types, fiber cells in Arabidopsis thaliana, wood, and bamboo are stiffer and mechanically support the stem/trunk/culm ${ }^{37-40}$. Thus, given their secondary cell wall morphology, S. lepidophylla stem cortical cells most likely act like fiber cells, providing structural support and reinforcement to the stem.

Cell wall elasticity differs between adaxial and abaxial stem sides. Cross-sections from five regions were selected, and indentation responses of cortical cell walls were retrieved at $250 \mathrm{~Hz}$ for both adaxial and abaxial areas, thus offering a means of comparison between the two stem sides (Fig. 3; Table 1). Five to ten cells were tested in each region and stem side. Between 4096 to 16384 points were examined for each cell wall (Fig. 3A). Graphs of indentation force and elastic modulus distribution were generated for each indented position in a given cell wall. Figure 3B illustrates the interaction between the AFM probe and the tissue as the probe is pushed on the sample surface up to a certain indentation depth; the area within their loading and unloading paths denotes the dissipation energy. In the apical stem region, for a given indentation depth on any section, the maximum average force measured within an abaxial cortical cell $(\sim 200-250 \mathrm{nN})$ was above the value obtained for an adaxial cortical cell $(\sim 100-140 \mathrm{nN})$, indicating higher stiffness of abaxial tissue relative to adaxial tissue. The distributions 

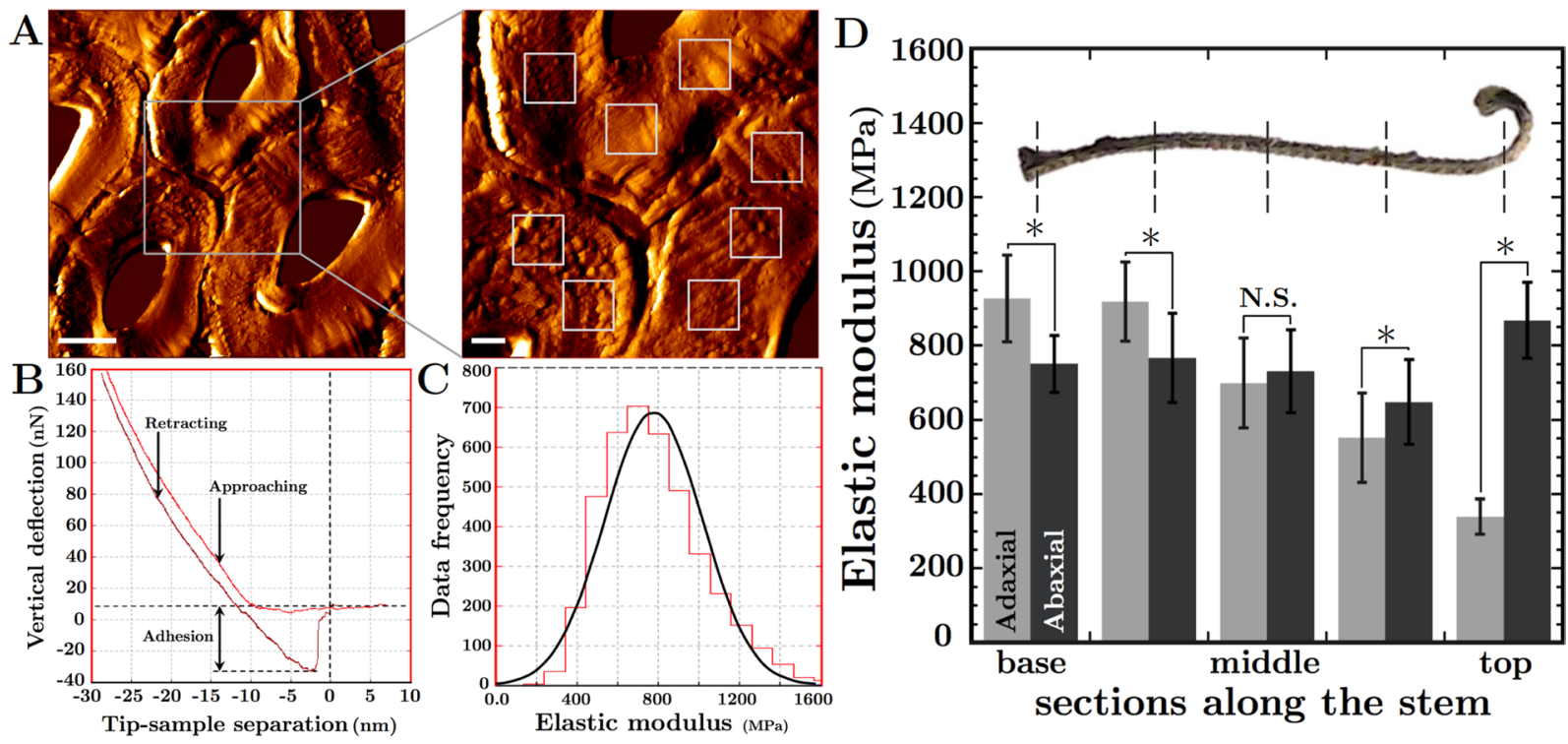

Figure 3. Stiffness of Cortical Cell Walls in the S. lepidophylla Stem. (A-C) Representative AFM results from scanning and indenting an apical cortical cell from an inner stem at the indentation frequency of $250 \mathrm{~Hz}$. (A) Topological scan showing the cell walls of three neighbouring adaxial cells and the areas chosen for indentation (inset). Eight representative force maps within an apical adaxial cortical cell from an inner stem are shown. $128 \times 128$ indentation points were tested in areas of $1-10 \mu \mathrm{m}^{2}$. Scale bars from left to right represent $5 \mu \mathrm{m}$ and $2 \mu \mathrm{m}$. (B) A typical force spectroscopy curve for a single indentation point showing adhesion forces of $\sim 40 \mathrm{nN}$ (distance of detachment $\sim 30 \mathrm{~nm}$ ). Both approaching and retracting curves are shown; (C) Histogram showing the average distribution of elastic modulus $E$ across cell wall indentations in a single area. The red graph represents the experimental measures, and the solid dark curve is the Gaussian curve of the best fit; (D) Image showing the five regions along the length of inner stems in a dry state used for AFM indentation analysis and a graph of the results obtained in each region for the adaxial versus abaxial sides of the stem. Significant differences between stem sides within each point are indicated by $*(\mathrm{p}<0.05$; Table 1$)$. N.S. represents no significant difference $(\mathrm{p}>0.05)$.

\begin{tabular}{|l|l|l|l|l|l|}
\hline $\begin{array}{l}\text { Cortical } \\
\text { Tissue }\end{array}$ & $\begin{array}{l}\text { Elastic Modulus } \\
\text { Top }(\mathbf{M P a})\end{array}$ & $\begin{array}{l}\text { Elastic Modulus Top- } \\
\text { Middle }(\mathbf{M P a})\end{array}$ & $\begin{array}{l}\text { Elastic Modulus } \\
\text { Middle }(\mathbf{M P a})\end{array}$ & $\begin{array}{l}\text { Elastic Modulus } \\
\text { Middle-Base }(\mathbf{M P a})\end{array}$ & $\begin{array}{l}\text { Elastic Modulus } \\
\text { Base }(\mathbf{M P a})\end{array}$ \\
\hline Adaxial & $\begin{array}{l}\mathbf{3 3 9 . 2 8} \pm \mathbf{1 3 . 2 9} \\
\mathrm{p}=0.00005\end{array}$ & $\begin{array}{l}\mathbf{5 5 0 . 7 4} \pm \mathbf{1 5 . 1 9} \\
\mathrm{p}=0.00009\end{array}$ & $699.38 \pm 21.81$ & $\begin{array}{l}\mathbf{9 1 9 . 0 0} \pm \mathbf{1 4 . 6 3 *} \\
\mathrm{p}=0.00136\end{array}$ & $\begin{array}{l}\mathbf{9 2 7 . 0 8} \pm \mathbf{2 1 . 1 2} \\
\mathrm{p}=0.00144\end{array}$ \\
\hline Abaxial & $\begin{array}{l}\mathbf{8 6 7 . 5 2} \pm \mathbf{3 1 . 5 0} \\
\mathrm{p}=0.00005\end{array}$ & $\begin{array}{l}\mathbf{6 3 3 . 7 2} \pm \mathbf{1 9 . 9 6} \\
\mathrm{p}=0.00009\end{array}$ & $718.96 \pm 27.71$ & $\begin{array}{l}\mathbf{7 7 8 . 6 1} \pm \mathbf{1 4 . 2 7} * \\
\mathrm{p}=0.00136\end{array}$ & $\begin{array}{l}\mathbf{7 3 8 . 3 4} \pm \mathbf{2 3 . 8 4} \\
\mathrm{p}=0.00144\end{array}$ \\
\hline
\end{tabular}

Table 1. S. lepidophylla Cortical Cell Wall Elasticity. Five adaxial and five abaxial cells were indented for each stem region (apical [top], top-middle, middle, middle-basal and basal) at $250 \mathrm{~Hz}$. Differences between adaxial and abaxial stem regions were tested using two-sided Wilcoxon sign-rank tests with a cut-off of $\mathrm{p}=0.05$ and significant results are marked by *. Data are shown in terms of mean \pm standard error. At the stem base, adaxial cortical cell walls are significantly stiffer $(1.44 \mathrm{e}-03, \mathrm{p}<0.05)$ than abaxial cell walls, whereas the opposite is observed at the stem tip $(5.02 \mathrm{e}-05, \mathrm{p}<0.05)$.

on these graphs were consolidated and an average longitudinal elastic modulus $E$ for adaxial and for abaxial cortical cell walls for each stem region was calculated (Fig. 3B-D; Table 1). Significant stiffness differences were observed between adaxial and abaxial cell walls along the length of the stem, with the exception of the middle stem sections in which $E$ was comparable between adaxial and abaxial regions. Interestingly, while the value of $E$ in abaxial cortical cell walls remained roughly consistent along the length of the stem $(\sim 700-800 \mathrm{MPa})$, it was found to decrease steadily in adaxial cell walls moving from the mid-base region ( $920 \mathrm{MPa})$ to the tip of the stem ( 340 MPa) (Fig. 3; Table 1).

The gradient of stiffness in adaxial cortical cell walls follows a secondary cell wall developmental (SCW) gradient in which walls become thicker and increasingly lignified moving from stem tip to base, as reported in monocots such as bamboo, and eudicots such as $A$. thaliana and various tree species ${ }^{37,38,41}$. This type of stiffness gradient allows the upper portions of stems/trunks/culms to be flexible and bend more readily in response to environmental factors such as wind, while the stiffer base resists movement and prevents the plant from being uprooted ${ }^{42-44}$. What is novel about S. lepidophylla is that there is also an adaxial to abaxial gradient of SCW stiffness that likely promotes directional bending toward the adaxial side. These SCW stiffness changes are paired with differences in cell morphology and orientation, suggesting alternate development between the two sides of the stem ${ }^{11}$. This could be akin to the differential regulation of adaxial and abaxial developmental programs essential for correct 

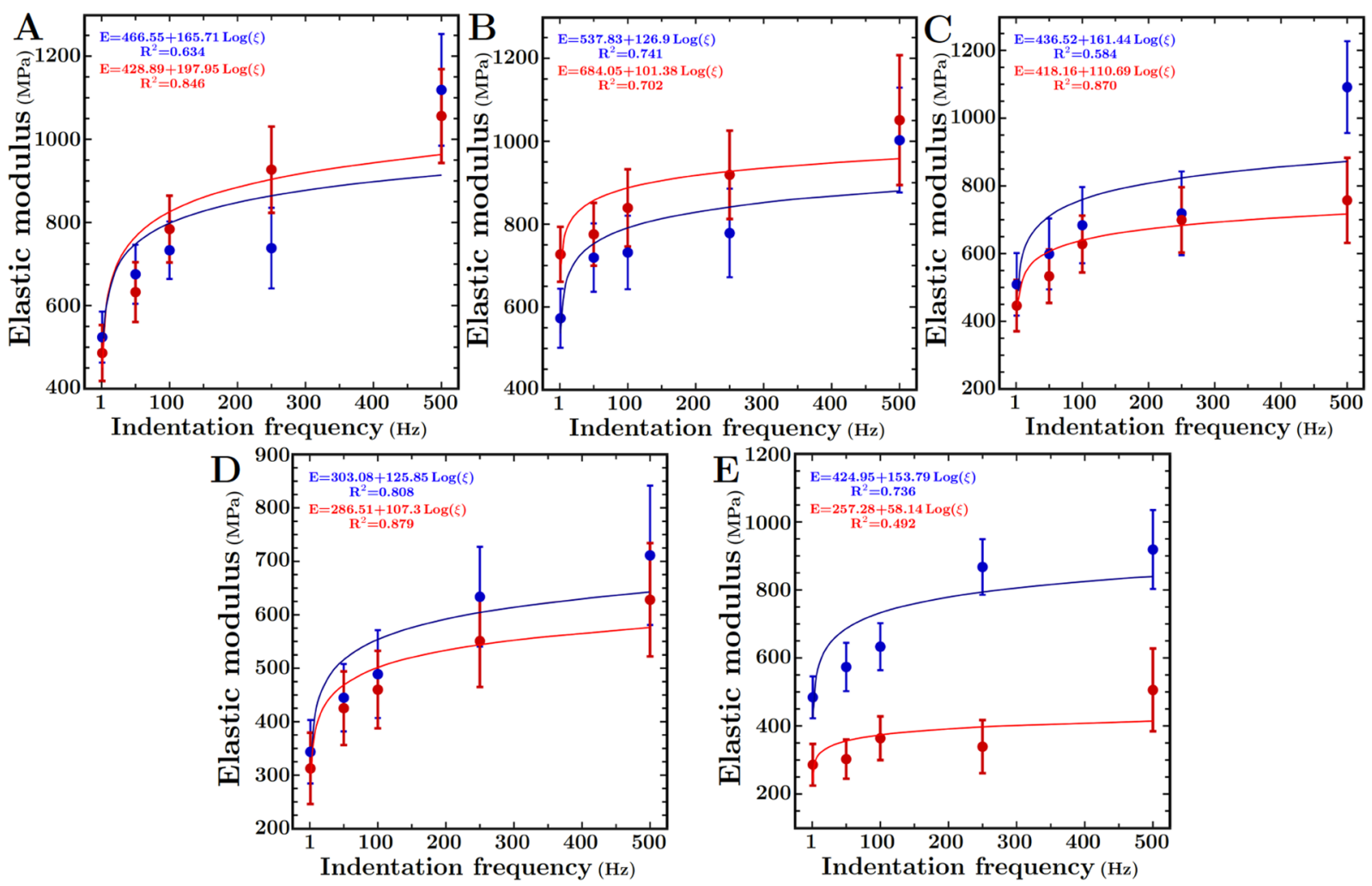

Figure 4. Elastic Modulus of Stem Regions Against Indentation Frequency. (A-E) Measured elastic moduli of adaxial and abaxial areas of basal (A), middle-basal (B), middle (C), apical-middle (D) and apical (E), regions at indentation frequencies of $1-500 \mathrm{~Hz}(\mathrm{Mean} \pm \mathrm{SD})$. The plots show the mean and standard error of the measured elastic modulus $E$ of all samples for given indentation rate $1 /\left(T_{e}+T_{r}\right)$, where $T_{e}$ is the extending time and $T_{r}$ the retracting time of the probe during indentation, which were set equal at each loading rate ${ }^{28,29}$. Adaxial elastic moduli in $\mathrm{MPa}$ are plotted with a logarithmic fit in red, while abaxial results are shown in blue. For apical stem, the mean value of the abaxial elastic modulus increased from $\sim 500 \mathrm{MPa}$ at $1 \mathrm{~Hz}$ to $\sim 850 \mathrm{MPa}$ at $500 \mathrm{~Hz}$, showing more than $\sim 70 \%$ increase. The mean value of the adaxial elastic modulus in the same region increased from $\sim 300 \mathrm{MPa}$ at $1 \mathrm{~Hz}$ to $\sim 500 \mathrm{MPa}$ at $500 \mathrm{~Hz}$, showing more than $\sim 65 \%$ increase. For the basal part of the stem, the increase in abaxial elastic modulus was more than $100 \%$ from $\sim 500 \mathrm{MPa}$ at $1 \mathrm{~Hz}$, to $\sim 1100 \mathrm{MPa}$ at $500 \mathrm{~Hz}$. In the same region, the increase in adaxial elastic modulus was about $100 \%$ from $\sim 480 \mathrm{MPa}$ at $1 \mathrm{~Hz}$, to $\sim 1050 \mathrm{MPa}$ at $500 \mathrm{~Hz}$.

patterning of planar organs such as leaves in other plant species, such as A. thaliana ${ }^{45}$. Based on such a model, differences in the onset and extent of SCW differentiation could lead to a steeper gradient of stiffness from base to tip in adaxial stem cortex, and a relatively subtler gradient in abaxial stem cortex. Taken together, in S. lepidophylla, these two perpendicular SCW stiffness gradients (longitudinal and adaxial-abaxial) are expected to work together to allow the stem tip to curl tightly on itself toward the adaxial side (least stiff region of the stem) while restricting movement at the stem base, and to direct movement away from the abaxial side (Fig. 1C) $)^{10,11}$.

A number of considerations need to be made to interpret the results obtained from AFM and other indentation techniques ${ }^{17,46,47}$. Of particular importance is the indentation depth and force relative to the thickness of the specimen. If the indentation is too deep or the forces are too large, there is a risk that the sample could be significantly damaged and/or that the observed results were influenced by the properties of the substrate underlying the section (i.e., a glass slide). To minimize these factors, the samples were indented with low magnitude forces, below $500 \mathrm{nN}$, and the indentation depth chosen $(\sim 20-30 \mathrm{~nm})$ was smaller than both the thickness of the sample $(\sim 1 \mathrm{~mm})$ and the radius of the indenting sphere $(\sim 100 \mathrm{~nm})$. Another factor that must be considered when indenting living plant cell walls is the contribution of turgor (internal cell pressure on the cell wall from the fluid-filled vacuole) to the measured mechanical properties ${ }^{47-49}$. Inner S. lepidophylla stems, still undergoing development, are living ${ }^{9,11}$. Thus, to reduce the influence of turgor on the measured cell wall $E$ of cortical cells, samples were air-dried to a relative water content of $\sim 5 \%$ prior to indentation.

Cortical cell walls are viscoelastic and show increasing stiffness at higher frequencies. Since biological materials are complex and often exhibit viscoelastic behaviour, we investigated the loading rate dependency of the elastic behaviour of S. lepidophylla cell walls. Additional indentation tests were performed at five indentation frequencies $(1,50,100,250$ and $500 \mathrm{~Hz})$ on the regions and areas previously tested (Fig. 4) ${ }^{28,50}$. Similar to the testing at a single frequency $[250 \mathrm{~Hz}]$, the elastic moduli of abaxial (lower) cell walls remained relatively constant along the length of the stem, while those of the adaxial cortical cell walls were significantly lower 


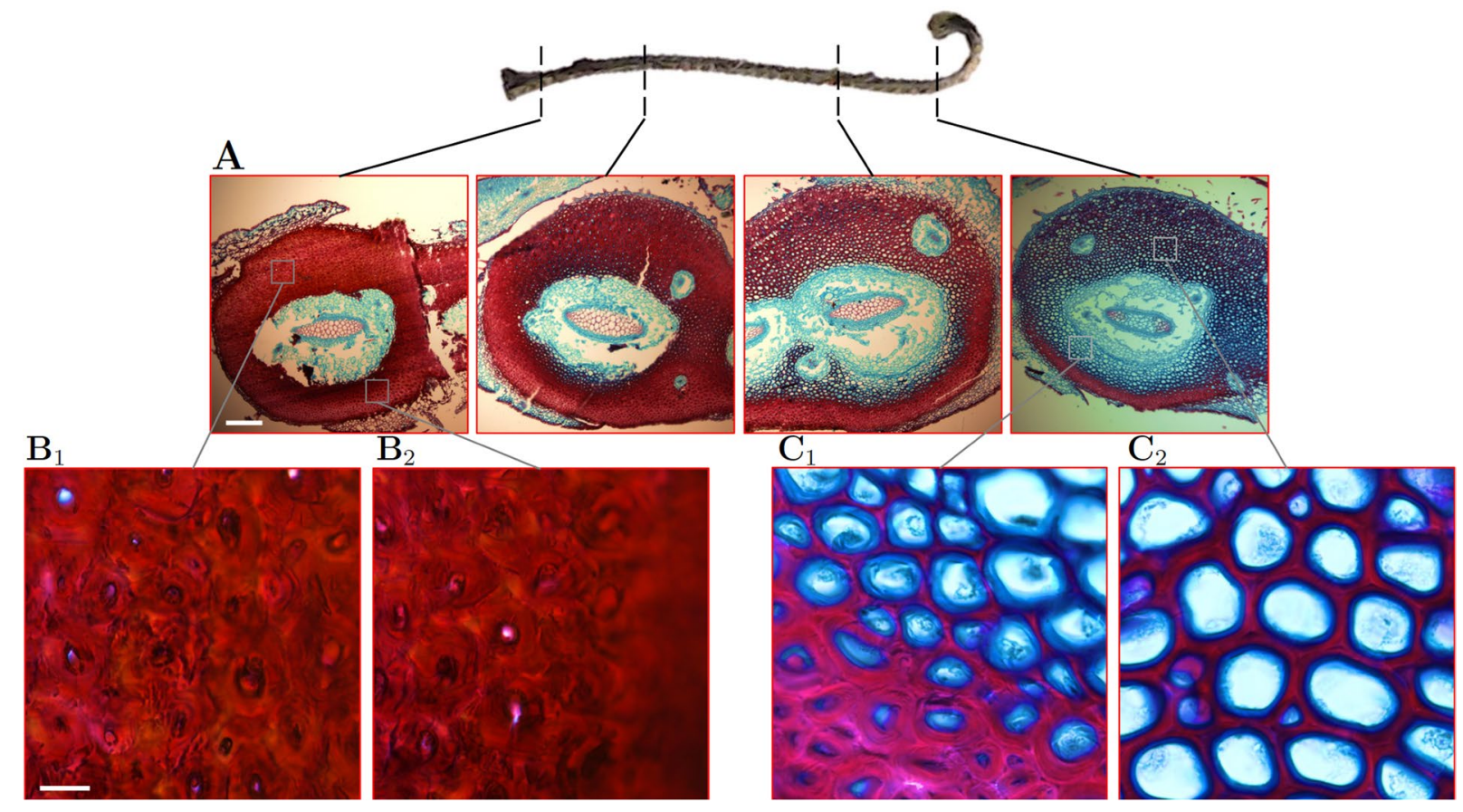

Figure 5. S. lepidophylla Cortical Cell Wall Composition. (A) Transverse sections from four inner stem regions (apical, apical-middle, middle-basal, and basal) stained with alcian blue (blue), and with safranin O (red) to detect lignin. Stem cortex became increasingly stained for safranin O moving from stem tip to base. At the tip, abaxial cortex is visibly more stained with safranin $O$ than adaxial cortex. At the base, both stem sides appear to stain strongly with safranin $\mathrm{O}$. Apical-middle and middle-basal regions show intermediate staining between what is observed at the stem tip and base. Scale bar: $200 \mu \mathrm{m} .\left(\mathbf{B}_{1}, \mathbf{B}_{2}\right)$ High magnification images of adaxial and abaxial cell walls in basal stem regions. $\left(\mathbf{C}_{1}, \mathbf{C}_{2}\right)$ High magnification images of abaxial and adaxial cell walls in apical stem regions. In the apical region in adaxial cells, safranin $\mathrm{O}$ stains the outer secondary wall layers, while the counterstain, alcian blue, stains the inner secondary wall layer. A similar pattern is seen in abaxial cortical cells near the center of the stem, but cells near the stem periphery show more layers with safranin $\mathrm{O}$ staining and a narrow inner layer stained with alcian blue. In contrast, adaxial and abaxial cell wall layers in the basal stem region almost exclusively stain with safranin $\mathrm{O}$, with only a very small inner layer stained with alcian blue. Scale bar: $10 \mu \mathrm{m}$.

in the apical region compared to the stem base. For a given indentation depth, $\delta$, below $50 \mathrm{~nm}, E$ increased with the indentation frequency, showing the dependence of tissue stiffness on loading rate. Further, for each prescribed indentation depth, the maximum indentation load increased with the loading frequency, confirming high values of the elastic modulus at high loading rates. The change in elastic modulus at given indentation frequencies is typical of biological samples and suggests that $S$. lepidophylla cortical cell walls along the length of the stem are viscoelastic ${ }^{28,29,50}$. The large standard errors of the experimental data, in particular at high frequencies, can be attributed to tissue heterogeneity, which varies with position in all regions within the stem. Our results are consistent with the viscoelastic behaviour observed with nano-indentation, including AFM, of dried secondary cell walls in flax fibres and wood ${ }^{51-53}$.

Cell wall composition resembles gelatinous fibers of tension wood, coiling vines, and ice plant seed capsules. It is well established that cell wall composition affects cell wall mechanical properties, including stiffness ${ }^{31,54,55}$. We thus examined cortical cell wall composition along the length of inner S. lepidophylla stems on both adaxial and abaxial sides. We were particularly interested in identifying the existence of any relation between the cell wall composition and the cell wall layering patterns observed with AFM (Fig. 3) and TEM (Supplementary Fig. 2).

Cell walls were stained with safranin $\mathrm{O}$ to detect polyphenolics, including lignin, and counter-stained with alcian blue to detect other cell wall materials (Fig. 5A,B) ${ }^{19,56,57}$. In all sections, the outermost SCW layers of S. lepidophylla cortex stained with safranin O, while the innermost SCW layer stained with alcian blue (Fig. 5B). Increasing wall thickness from stem tip to base corresponded with increasing SCW layers stained with safranin $\mathrm{O}$, while alcian blue continued to exclusively stain the innermost SCW layer ${ }^{11}$. Further investigation with other cell wall stains and antibodies revealed that the SCW inner layer stained by alcian blue appears to be predominantly enriched in cellulose (Supplementary Fig. 3) and hemicellulose (Supplementary Fig. 4), but not pectin (Supplementary Fig. 5).

While this compositional pattern does not appear to correspond to the SCW morphological layering observed with AFM and TEM, it does resemble the established bilayer-like cell wall composition of gelatinous (G) fiber and G- fiber-like cells in other species, such as tension wood, coiling vines, and ice plant seed capsules ${ }^{58-61}$. G-fiber 
and G-fiber-like cells differ from normal fiber cells by the presence of a tertiary hydrophilic, gelatinous layer in their cell wall that is surrounded by a lignified SCW layer. In both tension wood and coiling vines, the gelatinous layer is pectin-rich ${ }^{58,59}$, while in ice plant seed capsules, this layer is predominantly composed of cellulose $\mathrm{e}^{60}$. In all these species, G-fibers lead to directional organ movement, and, in the case of ice plants, reversible deformation. Given the compositional bilayer similarity, and the (hemi)cellulose inner layer that resembles the cellulose-rich inner layer of ice plant seed capsules cells, S. lepidophylla cortical cell composition likely contributes to reversible stem deformation through swelling and shrinking of its (hemi)cellulose inner SCW layer. The degree of swelling/shrinking is most likely determined by the proportion of lignin:(hemi)cellulose layers present in the wall, resulting from developmental gradients of SCW lignin deposition and cell wall thickness (i.e., increased SCW lignification and cell wall thickness as cells mature $)^{38}$. A polyphenolic matrix that is deposited around cell wall polysaccharides, lignin could be directly affecting SCW stiffness and/or preventing cell wall hydration/swelling due to its hydrophobicity ${ }^{11}$. In the adaxial apical cortex where walls are thinnest and the proportion of lignin layers is qualitatively similar to that of (hemi)cellulose, swelling probably is not as restricted as it might be in the adaxial basal cortex where cell walls are thicker and the proportion of lignified layers is higher. This would give rise to differential swelling leading to stem curling toward the adaxial side, and a gradient of curling along the stem length.

\section{Conclusions}

S. lepidophylla is a desiccation tolerant plant used as a model to study hierarchical, water-responsive deformation. Previous studies at the organ and tissue levels suggest morphological and compositional properties leading to reversible stem curling ${ }^{10,11}$. Here, we examine cell wall morphology, mechanics and composition to inform the contribution of cortical SCW s to the overall curling of inner S. lepidophylla stems. Using AFM, we identified cortical cell wall stiffness gradients from stem tip to base, and also between adaxial and abaxial stem sides (Fig. 3, Table 1). Changes in SCW layer morphology (Fig. 2) and composition (Fig. 5) between adaxial and abaxial stem sides, as well as composition along the stem length, might contribute to the observed elasticity gradients. Further, G-fibre-like bilayer composition of cortical cell walls combined with the presence of perpendicular stiffness gradients could contribute to differential swelling between adaxial and abaxial stem sides and along the stem length, resulting not only in directional bending, but also linear stem curling. These perpendicular gradients likely result from established SCW developmental gradients (e.g., increasing stem tip to base lignification [Fig. 2] and cell wall thickness), and separate adaxial and abaxial differentiation programs ${ }^{37,38,41}$. S. lepidophylla has provided the opportunity to study three-dimensional gradients at small length scales that lead to macro-level actuation. The cell wall properties identified here could be explored further with computational models to extract features for the development of synthetic actuators with improved performance and structure at the micro-level ${ }^{2,3}$.

Received: 14 May 2019; Accepted: 27 December 2019;

Published online: 16 January 2020

\section{References}

1. Burgert, I. \& Fratzl, P. Actuation systems in plants as prototypes for bioinspired devices. Philos. Trans. Royal Soc. A 367, 1541-1557 (2009).

2. Naleway, S. E., Porter, M. M., McKittrick, J. \& Meyers, M. A. Structural design elements in biological materials: application to bioinspiration. Adv. Mater. 27, 5455-5476 (2015).

3. Lv, C. et al. Humidity-responsive actuation of programmable hydrogel microstructures based on 3D printing. Sens. Actuator B-Chem. 259, 736-744 (2018).

4. Erb, R. M., Sander, J. S., Grisch, R. \& Studart, A. Self-shaping composites with programmable bioinspired microstructures. Nat. Commun. 4, 1712 (2013).

5. Shtein, I., Bar-On, B. \& Popper, Z. A. Plant and algal structure: from cell walls to biomechanical function. Physiol. Plant. 164(1), 56-66 (2018)

6. Elbaum, R. \& Abraham, Y. Insights into the microstructures of hygroscopic movement in plant seed dispersal. Plant Sci. 223, 124-133 (2014)

7. Borowska-Wykret, D. et al. Gradient of structural traits drives hygroscopic movements of scarious bracts surrounding Helichrysum bracteatum capitulum. Ann. Bot. 119(8), 1365-1383 (2017)

8. Hofhuis, H. et al. Morphomechanical innovation drives explosive seed dispersal. Cell 166(1), 222-233 (2016)

9. Brulé, V., Rafsanjani, A., Pasini, D. \& Western, T. L. Hierarchies of plant stiffness. Plant Sci. 250, 79-96 (2016).

10. Rafsanjani, A., Brulé, V., Western, T. L. \& Pasini, D. Hydro-responsive curling of the resurrection plant Selaginella lepidophylla. Sci. Rep. 5, 8064 (2015).

11. Brulé, V., Rafsanjani, A., Asgari, M., Western, T. L. \& Pasini, D. Three-dimensional functional gradients direct stem curling in the resurrection plant Selaginella lepidophylla. J. Royal Soc. Interface 16(159), 20190454 (2019).

12. Lebkuecher, J. G. \& Eickmeier, W. G. Reduced photoinhibition with stem curling in the resurrection plant Selaginella lepidophylla. Oecologia 88, 597-604 (1991).

13. Lebkuecher, J. G. \& Eickmeier, W. G. Physiological benefits of stem curling for resurrection plants in the field. Ecology 74, 1073-1080 (1993).

14. Niklas, K. J. Plant biomechanics: an engineering approach to plant form and function (University of Chicago Press, 1992).

15. Vincent, J. F. V. Biomechanics-materials. (Oxford University Press, New York, 1992).

16. Cosgrove, D. J. Plant cell wall extensibility: connecting plant cell growth with cell wall structure, mechanics, and the action of wallmodifying enzymes. J. Exp. Bot. 67, 463-476 (2015).

17. Milani, P., Braybrook, S. A. \& Boudaoud, A. Shrinking the hammer: micromechanical approaches to morphogenesis. J. Exp. Bot. 64, 4651-4662 (2013).

18. Vogler, H., Felekis, D., Nelson, B. J. \& Grossniklaus, U. Measuring the mechanical properties of plant cell walls. Plants 4, 167-182 (2015).

19. Ruzin, S. E. Plant microtechnique and microscopy. (Oxford University Press, New York, 1999).

20. Young, R. E. et al. Analysis of the Golgi apparatus in Arabidopsis seed coat cells during polarized secretion of pectin-rich mucilage. Plant Cell 20, 1623-1638 (2008).

21. McCartney, L., Marcus, S. E. \& Knox, J. P. Monoclonal antibodies to plant cell wall xylans and arabinoxylans. J. Histochem. Cytochem. 53(4), 543-546 (2005). 
22. Knox, J. P., Linstead, P. J., King, J., Cooper, C. \& Roberts, K. Pectin esterification is spatially regulated both within cell walls and between developing tissues of root apices. Planta 181(4), 512-521 (1990).

23. Knox, J. P., Linstead, P. J., King, J., Cooper, J. P. C. \& Roberts, K. Developmentally regulated epitopes of cell surface arabinogalactan proteins and their relation to root tissue pattern formation. Plant J. 1(3), 317-326 (1991).

24. Gierlinger, N., Keplinger, T. \& Harrington, M. Imaging of plant cell walls by confocal Raman microscopy. Nat. Protoc. 7(9), 1694 (2012).

25. Hutter, J. L. \& Bechhoefer, J. Calibration of atomic-force microscope tips. Rev. Sci. Instrum. 64(7), 1868-1873 (1993).

26. Walters, D. et al. Short cantilevers for atomic force microscopy. Rev. Sci. Instrum. 67(10), 3583-3590 (1996).

27. Johnson, K. L. Contact Mechanics (Cambridge University Press, 1987).

28. Asgari, M. Micro-mechanical, continuum-mechanical, and AFM-based descriptions of elasticity in open cylindrical micellar filaments. Soft Matter 13, 7112-7128 (2017).

29. Asgari, M., Abi-Rafeh, J., Hendy, G. N. \& Pasini, D. Material anisotropy and elasticity of cortical and trabecular bone in the adult mouse femur via AFM indentation. J. Mech. Behav. Biomed. Mater. 93, 81-92 (2019).

30. Latifi, N., Asgari, M., Vali, H. \& Mongeau, L. A tissue-mimetic nano-fibrillar hybrid injectable hydrogel for potential soft tissue engineering applications. Sci. Rep. 8, 1047 (2018).

31. Gibson, L. J. The hierarchical structure and mechanics of plant materials. J. R. Soc. Interface 9, 2749-2766 (2012).

32. Burgert, I. \& Dunlop, J. W. C. Micromechanics of cell walls. Mechanical integration of plant cells and plants, Springer, 27-52 (2011).

33. Zhong, R. \& Ye, Z.-H. Secondary cell walls: biosynthesis, patterned deposition and transcriptional regulation. Plant Cell Physiol. 56, 195-214 (2014)

34. Liu, D., Song, J., Anderson, D. P., Chang, P. R. \& Hua, Y. Bamboo fiber and its reinforced composites: structure and properties. Cellulose 19, 1449-1480 (2012).

35. Parameswaran, N. \& Liese, W. On the fine structure of bamboo fibres. Wood Sci. Technol. 10, 231-246 (1976)

36. Zou, L., Jin, H., Lu, W.-Y. \& Li, X. Nanoscale structural and mechanical characterization of the cell wall of bamboo fibers. Mater. Sci. Eng. C. 29, 1375-1379 (2009).

37. Tan, T. et al. Mechanical properties of functionally graded hierarchical bamboo structures. Acta Biomater. 7, 3796-3803 (2011).

38. Zhong, R., Taylor, J. J. \& Ye, Z.-H. Disruption of interfascicular fiber differentiation in an Arabidopsis mutant. Plant Cell 9, 2159-2170 (1997).

39. Habibi, M. K., Samaei, A. T., Gheshlaghi, B., Lu, J. \& Lu, Y. Asymmetric flexural behavior from bamboo's functionally graded hierarchical structure: underlying mechanisms. Acta Biomater. 16, 178-186 (2015).

40. Persson, K. Micromechanical modelling of wood and fibre properties. Dissertation, Lund University (2000).

41. Barra-Jiménez, A. \& Ragni, L. Secondary development in the stem: when Arabidopsis and trees are closer than it seems. Curr. Opin. Plant Biol. 35, 145-151 (2017).

42. Dixon, P. G. \& Gibson, L. J. The structure and mechanics of Moso bamboo material. J. R. Soc. Interface 11, 321 (2014).

43. Gardiner, B., Berry, P. \& Moulia, B. Wind impacts on plant growth, mechanics and damage. Plant Sci. 245, 94-118 (2016).

44. Ghavami, K., Rodrigues, C. S. \& Paciornik, S. Bamboo: functionally graded composite material. Asian J. Civil Eng. 4, 1-10 (2003).

45. Fukuda, H. Signals that control plant vascular cell differentiation. Nat. Rev. Mol. Cell Biol. 5, 379 (2004).

46. Routier-Kierzkowska, A.-L. et al. Cellular force microscopy for in vivo measurements of plant tissue mechanics. Plant Physiol. 158(4), 1514-1522 (2012).

47. Braybrook, S. A. Measuring the elasticity of plant cells with atomic force microscopy. Methods Cell Biol. 125, 237-254 (2015).

48. Beauzamy, L., Derr, J. \& Boudaoud, A. Quantifying hydrostatic pressure in plant cells by using indentation with an atomic force microscope. Biophys. J. 108, 2448-2456 (2015).

49. Malgat, R., Faure, F. \& Boudaoud, A. A mechanical model to interpret cell-scale indentation experiments on plant tissues in terms of cell wall elasticity and turgor pressure. Front. Plant Sci. 7, 1351 (2016).

50. Asgari, M., Latifi, N., Heris, H. K., Vali, H. \& Mongeau, L. In vitro fibrillogenesis of tropocollagen type III in collagen type I affects its relative fibrillar topology and mechanics. Sci. Rep. 7, 1392 (2017).

51. Engelund, E. T. \& Svensson, S. Modelling time-dependent mechanical behaviour of softwood using deformation kinetics. Holzforschung 65, 231-237 (2011).

52. Yamashita, M., Yoshida, M., Matsuo, M., Sato, S. \& Yamamoto, H. Observations of Wood Cell Walls with a Scanning Probe Microscope. Mater. Sci. Appl. 7, 644 (2016).

53. Keryvin, V. et al. Analysis of flax fibres viscoelastic behaviour at micro and nano scales. Compos Part A Appl. Sci. Manuf. 68, 219-225 (2015).

54. Cosgrove, D. J. \& Jarvis, M. C. Comparative structure and biomechanics of plant primary and secondary cell walls. Front Plant Sci. 3, 204 (2012).

55. Bidhendi, A. J. \& Geitmann, A. Relating the mechanics of the primary plant cell wall to morphogenesis. J. Exp. Bot. 67, 449-461 (2015).

56. Bond, J., Donaldson, L., Hill, S. \& Hitchcock, K. Safranine fluorescent staining of wood cell walls. Biotech. Histochem. 83, 161-171 (2008).

57. Marjamaa, K. et al. Developmental lignification and seasonal variation in $\beta$-glucosidase and peroxidase activities in xylem of Scots pine, Norway spruce and silver birch. Tree Physiol. 23, 977-986 (2003).

58. Bowling, A. J. \& Vaughn, K. C. Immunocytochemical characterization of tension wood: gelatinous fibers contain more than just cellulose. Am. J. Bot. 95, 655-663 (2008).

59. Bowling, A. J. \& Vaughn, K. C. Gelatinous fibers are widespread in coiling tendrils and twining vines. Am. J. Bot. 96, 719-727 (2009).

60. Harrington, M. J. et al. Origami-like unfolding of hydro-actuated ice plant seed capsules. Nat. Commun. 2, 337 (2011).

61. Meloche, C. G., Knox, J. P. \& Vaughn, K. C. A cortical band of gelatinous fibers causes the coiling of redvine tendrils: a model based upon cytochemical and immunocytochemical studies. Planta 225, 485-498 (2007).

\section{Acknowledgements}

M.A. acknowledges support under the Postdoctoral Fellowships Program (NSERC PDF \#516501-2018) from the Natural Sciences and Engineering Research Council of Canada. D.P. acknowledges support from the Natural Sciences and Engineering Research Council of Canada (NSERC), the Canadian Institutes of Health Research (CIHR), and the Canadian Foundation for Innovation (CFI \#229251). T.L.W. acknowledges NSERC Discovery Grant as well as infrastructure provided by the Integrated Quantitative Biology Initiative, Canadian Foundation of Innovation project 33122. D.P. and T.L.W. acknowledge FRQNT Recherche en Equipe Grant.

\section{Author contributions}

M.A., V.B., T.L.W. and D.P. conceived and designed the research. M.A. performed AFM imaging and indentation tests, data analysis and figure preparations. V.B. performed light and electron microscopy imaging and relevant data analysis. M.A. and V.B. drafted the manuscript. All authors participated in interpretation of results and manuscript editing. T.L.W. and D.P. supervised the work. M.A. and V.B. contributed equally to this work. 


\section{Competing interests}

The authors declare no competing interests.

\section{Additional information}

Supplementary information is available for this paper at https://doi.org/10.1038/s41598-019-57365-z.

Correspondence and requests for materials should be addressed to D.P.

Reprints and permissions information is available at www.nature.com/reprints.

Publisher's note Springer Nature remains neutral with regard to jurisdictional claims in published maps and institutional affiliations.

(c) (i) Open Access This article is licensed under a Creative Commons Attribution 4.0 International License, which permits use, sharing, adaptation, distribution and reproduction in any medium or format, as long as you give appropriate credit to the original author(s) and the source, provide a link to the Creative Commons license, and indicate if changes were made. The images or other third party material in this article are included in the article's Creative Commons license, unless indicated otherwise in a credit line to the material. If material is not included in the article's Creative Commons license and your intended use is not permitted by statutory regulation or exceeds the permitted use, you will need to obtain permission directly from the copyright holder. To view a copy of this license, visit http://creativecommons.org/licenses/by/4.0/.

(C) The Author(s) 2020 